\title{
O Uso da Tecnologia como Ferramenta de Compartilhamento e Preservação do Dialeto Indígena
}

\author{
Dener Guedes Mendonça ${ }^{1}$, Joselice Ferreira Lima ${ }^{1}$, Claudio Alexandre Gusmão ${ }^{1}$
}

\author{
${ }^{1}$ Instituto Federal do Norte de Minas Gerais (IFNMG) - Campus Januária-MG, Brasil \\ denerguedesbnb@yahoo.com.br, joselice.f.lima@gmail.com, \\ claudioagusmao@gmail.com
}

\begin{abstract}
The article discusses the use of technology in indigenous communities and treats the use of systems functioning as sharing tools and preservation of indigenous dialect. The methodology used was based on a descriptive discussion in order to assign and analyze the linguistic characteristics belonging to the indigenous people. He sought to understand how the existing technological resources can assist in the rescue and transmission of indigenous language. As a result presents a system to register the indigenous vocabulary of a tribe in order to share and preserve their linguistic culture. It is concluded that the technology can meet the needs of villages assisting in the maintenance process, preservation and restructuring their dialect.
\end{abstract}

Resumo: $O$ artigo aborda o uso da tecnologia em comunidades indígenas $e$ trata o uso de sistemas funcionando como ferramentas de compartilhamento $e$ preservação do dialeto indígena. A metodologia usada teve como base uma discussão descritiva de forma a atribuir e analisar as características linguísticas pertencentes ao povo indígena. Buscou-se compreender como os recursos tecnológicos existentes podem auxiliar no resgate e transmissão da língua indígena. Como resultado apresenta um sistema para registrar o vocabulário indígena de uma tribo com o propósito de compartilhar $e$ preservar a sua cultura linguística. Conclui-se que a tecnologia pode atender as necessidades das aldeias auxiliando no processo de manutenção, preservação e reestruturação de seu dialeto.

\section{Introdução}

$\mathrm{Na}$ sociedade atual as organizações sociais estão sujeitas a influências de várias naturezas, em alguns casos essas mudanças são mais constantes em função do fluxo de pessoas, acarretando em miscigenação ou até mesmo em perda do vocabulário, tais como nas aldeias indígenas. No passar dos anos a bagagem cultural desse povo vai sofrendo intervenções externas, a tecnologia como uma dessas interferências traz mudanças significativas, mas que podem ser utilizadas para ensinar e inclusive para o fortalecimento de sua identidade social. A tecnologia garante a inclusão entre culturas e no caso indígena pode funcionar como fortalecimento de seus costumes, dependendo é claro do uso que se faz dela.

Atualmente observa-se a crescente evolução tecnológica que aos poucos também chega ao ambiente educacional indígena, seja através dos aparatos eletrônicos ou inclusão digital. "A chegada do computador e a expansão da conectividade promoveu não a substituição por uma nova mídia, mas a união, a confluência das diversas mídias, passando a coexistirem e se absorverem [...] (Zednik, 2014, p. 01)”. Nas aldeias e comunidades indígenas que já possuem certo grau de desenvolvimento 


\section{CBIE-LACLO 2015}

Anais dos Workshops do IV Congresso Brasileiro de Informática na Educação (CBIE 2015)

tecnológico (telecentros de inclusão digital, internet e etc), a utilização do computador é crescente, seja na escrita de projetos sociais, acesso a internet, ou para o estudo.

Considerando o modo como cada comunidade vive, respeitando suas tradições e cultura no uso das tecnologias, já existem programas de computadores que registram seus vocabulários, "estudos empreendidos em vários continentes evidenciam que a apropriação da tecnologia, quando garante comunicação entre culturas, fortalece a persistência das diferenças culturais" (Gallois e Carelli, 1998, p. 2).

O uso de recursos computacionais já está sendo difundido em função das facilidades proporcionadas por meio da internet no uso de e-mails, redes sociais e etc. Entretanto, dentro desta realidade observa-se que a transmissão do conhecimento (cultura indígena) é feita de forma oral pelos índios, ainda há carência da utilização de recursos de documentação escrita de sua língua, tão pouco armazenar sua correta pronúncia. Incluir esses indivíduos nas novas tecnologias à medida que aprendem e reestruturam sua língua indígena não é simplesmente capacitá-los para que sejam capazes de interagir com as máquinas, mas é promover uma mudança social com foco na preservação de sua identidade cultural em especial de seu vocabulário.

Levando-se em conta o crescimento da população indígena em todo o mundo, onde há comunidades (tribos) longínquas que demandam por serviços específicos, fica em evidência a necessidade de investir em inovações tecnológicas, ou seja, sistemas informatizados que facilitem a comunicação e integração entre elas.

Neste contexto, a inovação neste artigo está em abordar a questão da preservação da cultura indígena através do uso da tecnologia e sistemas de informação como uma forma de armazenar, preservar e compartilhar a cultura indígena, em especial a língua desses povos. A relevância está na apresentação do Sistema para Catalogar Palavras Indígenas - SISCAPI, a fim de demonstrar como os recursos tecnológicos podem ser utilizados para a reestruturação das línguas indígenas e construção de uma comunidade voltada ao resgate cultural nas aldeias.

Além desta Introdução o artigo está estruturado da seguinte forma: a Seção 2 trata a tecnologia como meio para preservação cultural indígena, aborda sistemas de informação e iniciativas em tecnologia voltadas para a área discutida; na Seção 3 é apresentada a metodologia utilizada na pesquisa, juntamente com a coleta e análise de dados; a Seção 4 apresenta e discute a ferramenta criada com base nos problemas identificados neste trabalho e a Seção 5 faz as considerações finais referentes às abordagens feitas no decorrer deste artigo.

\section{A Tecnologia como Meio de Preservação da Cultura Indígena}

A tecnologia tem tido uma grande influência na sociedade, pois o mundo se encontra em processo de informatização em todos os níveis. O crescimento da internet, por exemplo, enriqueceu o papel do usuário, dotando-o com o potencial e a capacidade de produtor e intermediário de conteúdos.

A tecnologia da informação (TI) se faz presente em qualquer dispositivo capaz de oferecer recursos tecnológicos e computacionais para o armazenamento de dados e a geração de informações. O termo Tecnologia da Informação segundo Beal (2001), serve para designar o conjunto de recursos tecnológicos e computacionais para geração e uso da informação. Sendo a informação um bem que agrega valor a uma empresa ou a um 
indivíduo, é necessário fazer uso de recursos que manipulem essas informações de maneira apropriada, ou seja, é preciso utilizar ferramentas, sistemas ou outros meios que façam das informações um diferencial.

Neste contexto, as tecnologias, através dos sistemas de informação, trazem uma contribuição importante para a recuperação e a transmissão da cultura indígena. $\mathrm{Na}$ visão de Lima (2013, p. 130) esses sistemas "podem ser entendidos como um meio de coletar (dados), processar e disponibilizar a informação". Apresentam-se como soluções para processos de armazenamento e produção de informações a partir da transformação de dados e através da aplicação do conhecimento humano.

Dentro desta temática abordamos o caso do povo Xakirabá, oriundo de uma comunidade indígena no Norte de Minas Gerais, de modo a propor o uso da tecnologia (sistema de informação) no armazenamento e resgate do dialeto indígena ainda existente nessa aldeia. O povo Xakriabá possui ramificações diversas que ajudaram a constituir sua identidade e vocabulário que inclusive é determinante em sua classificação.

Os Xakriabá são identificados como Jê, subdivisão Akwê. Vivem hoje, após intensa luta pela posse da terra contra posseiros e fazendeiros da região, na denominada Reserva Indígena Xakriabá, demarcada e homologada, localizada no município de São João das Missões-MG (Escobar, 2011, p. 02).

Reviver a língua indígena dos Xakriabás permite resgatar a história dessa comunidade, facilitando o repasse das palavras indígenas ainda faladas, garantindo que novas gerações tenham acesso a todo esse material linguístico. Nesse sentido os recursos tecnológicos podem constituir como meios de promover e facilitar a disseminação e aprendizado desses vocabulários. A tecnologia e as informações geradas com os sistemas de informação enquanto ferramentas é um artefato que não traz embutido o engessamento dos dados, as pessoas tem toda a liberdade para usá-lo segundo suas respectivas intenções e para seus próprios fins. A produção de conteúdo, seu registro e difusão nos âmbitos de governo, da sociedade e dos indivíduos irão refletir as diversidades culturais e da língua assim como o resgate da memória ainda pouco registrada.

O uso da tecnologia e sistemas de informação, já mostrou sua utilidade social inclusive em ambientes indígenas. Nos próximos tópicos são discutidos sistemas de informação a gestão do conhecimento envolvendo a questão da tecnologia e do conhecimento indígena.

\subsection{Sistemas de Informação e a Gestão do Conhecimento}

A Tecnologia da Informação (TI) está fundamentada nos seguintes componentes: "Hardware e seus dispositivos e periféricos; Software e seus recursos; Sistemas de telecomunicações; Gestão de dados e informações" (Beal 2001, p. 1 e 2). Já as Tecnologias de Informação e Comunicação (TIC) abrangem o conjunto desses elementos participantes da tecnologia da informação e permitem de forma dinâmica que informações sejam produzidas, divulgadas e compartilhadas praticamente em tempo real. A gestão dessa Tecnologia da Informação abrange o conjunto de atividades e projetos criados com tais recursos computacionais. A informação é um patrimônio da sociedade e está interligada a sua preservação e continuidade. Cada comunidade deve utilizar a gestão da informação de acordo as suas necessidades específicas. Os 


\section{CBIE-LACLO 2015}

Anais dos Workshops do IV Congresso Brasileiro de Informática na Educação (CBIE 2015)

indivíduos devem então desenvolver possibilidades de uso para tais tecnologias da informação, perpassando por sua implementação até sua disseminação social.

Conceitos e definições relacionados a dados, informações e conhecimento devem ser elucidados na medida que entende-se por dado "[...] qualquer elemento identificado em sua forma bruta que, por si só, não conduz a uma compreensão de determinado fato ou situação" (Oliveira, 2002. p. 51). Mas permite a realização de cálculos, operações e quantificações. Já a informação "é o dado que foi processado e armazenado de forma compreensível para seu receptor [...]" (Padoveze (2000, p. 43) apud Nakagawa). Pode ser entendida como a contextualização dos dados numa estrutura de sintaxe, produzindo sentido, a partir de associações e do estabelecimento de relações entre eles. Nonaka e Takeuchi (1997) discutem a relação dados, informação e produção de conhecimento, para eles este último ainda se divide em tácito e explícito, "o conhecimento tácito é pessoal, específico ao contexto e, assim, difícil de ser formulado e comunicado. Já o conhecimento explícito ou codificado refere-se ao conhecimento transmissível em linguagem formal e sistemática" (apud Brito, 2008, p. 136).

Na visão de Nonaka e Takeuchi (1997), contudo o conhecimento tácito e o conhecimento explícito não são entidades totalmente separadas, e sim mutuamente complementares. O conhecimento humano é criado e expandido através da interação social entre o conhecimento tácito e o conhecimento explícito contribuindo para interação e conversão do conhecimento resultando em novos saberes. Compreende o conjunto completo de informações, dados e relações que levem as pessoas á tomada de decisão, à realização de tarefas e a criação de novas informações ou novos conhecimentos (apud Brito, 2008).

A organização de dados envolve um processo complexo que inclui, dentre outras construções a indexação, a atualização, a consulta, a publicação, a segurança, a recuperação de dados (backup), etc. Os principais tipos de repositórios de dados utilizados incluem arquivos, banco de dados, ferramentas diversas e também a gestão desses recursos e dados. Esses processos de transformação dos dados em informações e posteriormente geração do conhecimento acontece dentro de uma comunidade que interage entre si e que expande os limites para além de suas fronteiras, dando origem a questões importantes como a gestão e conversão do conhecimento.

"A gestão do conhecimento, portanto, teria como principal desafio a aquisição e a transferência do conhecimento pessoal do trabalhador (tácito) e do conhecimento declarativo (explícito) num processo de transformação interativa e em espiral (Brito, 2008, p. 137)". Afinal a criação do conhecimento é um processo dinâmico e contínuo. Assim através da tecnologia da informação teríamos de certa forma uma espiral do conhecimento a ser disseminado, conhecimento sendo trocado, convertido, combinado a outros já existentes e gerando outros novos para a sociedade. Para a gestão desse conhecimento acontecer é necessário capital humano, cultura organizacional e tecnologias da informação (sistemas) adequadas.

Para Davenport e Prusak (2003) "gestão do conhecimento pode ser entendida como uma proposta para desenvolver sistemas e processos que visem facilitar a captura, armazenamento e compartilhamento do conhecimento [...] (apud Albano, 2012, p. 245)". O uso de sistemas em rede possibilita então o compartilhamento de diversas informações, levando as comunidades a trocar conhecimento entre elas. A disponibilização de um vocabulário on-line, por exemplo, pode constituir-se em 
contribuições significativas para a preservação e perpetuação de costumes em diferentes níveis, variando-se, desde a transferência da palavra escrita até a oral. Esta abordagem pode proporcionar avanços enormes, pois um maior conjunto de dados é então compartilhado. Neste contexto os sistemas de informação se apresentam como soluções para processos de armazenamento e produção de informações a partir da transformação de dados e através da aplicação do conhecimento humano.

\subsection{Sistemas para Compartilhamento e Preservação de Línguas Indígenas}

A empresa Google lançou em 2012 um projeto para preservar e garantir a sobrevivência de dialetos indígenas no mundo, trata-se do "Idiomas em risco", um site que reúne um catálogo de culturas espalhadas pelo mundo (Kleina, 2012). A plataforma é colaborativa e depende que as pessoas apresentem as informações (vídeos, falas, imagens, histórias). Apesar dessa iniciativa as informações presentes no site são poucas e a colaboração tímida, tal fato pode ser explicado pela plataforma de interação ser confusa, muito tecnológica e pesada para os recursos tecnológicos utilizados pela grande maioria das pessoas.

No Brasil aparelhos celulares estão sendo usados para ajudar a coletar histórias da literatura oral indígena. O australiano Steven Bird, professor da Universidade de Melbourne, criou um sistema chamado Aikuma:

O aplicativo não utiliza a escrita e funciona com ícones. "Para a Amazônia, Bird levou 15 smartphones. Após gravar as histórias antigas e tradicionais, o aplicativo compartilha o conteúdo com os outros telefones da rede. Com o áudio disponível em todos os celulares, ele poderá então ser adaptado para o português por qualquer pessoa conectada à rede. A tradução é feita frase por frase. No final do processo, um CD será gravado com a história e a tradução (Neher, 2013, p. 01).

O aplicativo se preocupa com o áudio, mas não possui a possibilidade de armazenamento escrito da palavra, além disso, o produto final é um $\mathrm{CD}$, dificultando a possibilidade de inserção de novas informações. É necessário lembrar a importância do registro escrito do vocabulário de tais comunidades que representam um material importante para estudo da língua, aprendizado inclusive oral e preservação para repasse.

Apesar do pensamento popular de que os novos aparatos tecnológicos acabam com a cultura tradicional, usar a tecnologia como meio de preservação dos dialetos indígenas é uma forma inteligente de permitir que ambas coexistam mutuamente e que ao invés de se excluírem, trabalhem conjuntamente para a preservação cultural indígena.

\section{Metodologia}

No desenvolvimento deste artigo, optou-se pela metodologia qualitativa tendo como método a pesquisa exploratória descritiva de forma a atribuir e analisar as características linguísticas pertencentes ao povo indígena. Foram utilizados levantamentos bibliográficos e documentais como referenciais teóricos, e por fim, utilizada a observação sistemática com entrevista moradores da aldeia Xakriabá. Esta metodologia teve como foco se aprofundar na interpretação do fenômeno linguístico indígena, buscando compreender esta perspectiva do ponto de vista dos participantes analisados.

\footnotetext{
${ }^{1}$ Projeto Idiomas em Risco - http://www.endangeredlanguages.com/
} 


\subsection{Coleta de Dados}

As entrevistas combinadas com a observação e pesquisa ajudaram a identificar o problema da falta de registro escrito das línguas indígenas. Abaixo listamos e discutimos os principais problemas identificados na coleta de dados:

I - Registro escrito inexistente ou pouco efetivo da língua indígena: o povo Xakriabá apesar de ainda falar sua língua indígena de origem não a registra efetivamente, poucos escritos e palavras Xakriabás são verdadeiramente encontradas e grafadas. Não foi encontrado material indígena escrito pelos próprios Xakriabás, apenas algumas palavras levantadas por outros pesquisadores.

II - Transmissão apenas oral das palavras indígenas (pronúncia): a transmissão do conhecimento (língua) Xakriabá é realizada apenas oralmente e através de intercambio linguístico entre povos parentes, não é utilizado material escrito, não foi encontrado um padrão gráfico para representação escrita da língua.

II - Grande distância física entre povos que ainda falam a mesma língua indígena: os Xakriabás possuem correspondência linguística com o povo Xerente, estes por sua vez estão localizados no estado do Tocantins, a troca e aprendizagem linguística são feitas através de visitas entre os povos, mas apenas uma minoria dos Xakriabás consegue este contato e troca de conhecimentos. A distância atrapalha o contato e estudo linguístico entre esse dois povos.

IV - Falta de correspondência ou tradução entre a língua indígena e a língua portuguesa: os Xakriabás falam habitualmente o português, mas não fazem correspondência entre a língua indígena, são duas línguas que eles não fazem associação, assim o aprendizado fica mais difícil e demorado. É bem trabalhoso descobrir o significado de uma palavra Xakriabá, pois não existe correspondência e similaridade com o português.

V - A palavra é transmitida oralmente sem vinculação de uma identidade visual: apesar dos Xakriabás serem bons desenhistas e até mesmo trabalharem com conteúdo audiovisual na tribo, não existe vinculação deste material (desenhos e figuras) e a língua indígena. Falta uma correspondência e identidade visual para a língua Xakriabá.

VI - Inexistência da gravação (áudio) da pronúncia indígena palavra por palavra: o repasse é feito de falante para falante, apesar de existir CDs e materiais de áudio referentes a cantos e histórias Xakriabás, não foi encontrado o som gravado palavra por palavra, permitindo a delimitação de cada som referente a cada palavra para aprendizado e repasse.

VII - Falta de material (escrito ou on-line) contendo as palavras indígenas e informações: não foram encontrados materiais escritos sobre a língua Xakriabá, nem dicionários indígenas até o momento. Na web apenas algumas palavras Xakriabás são encontradas, mas elas já estão obsoletas, visto que foram colhidas por pesquisadores estrangeiros o que dificultou a escrita e conhecimento referente a real pronúncia da palavra indígena.

\subsection{Análise dos Dados Coletados}

Atualmente a língua Xakriabá é utilizada em cantos (músicas), falada entre alguns índios e reproduzida em escritas e representações esporádicas na comunidade. A escrita da língua Xakriabá quando é feita tem por base a adaptação a língua portuguesa, mas a 
grafia acontece de forma isolada. Algumas palavras Xakriabás inclusive podem ser observadas em conversas entre os índios nas redes sociais, entretanto não existe um documento (dicionário) ou material escrito para consulta.

Nesta pesquisa utilizou-se de termos específicos em mecanismos de busca (através de termos em inglês e português), a fim de identificar soluções tecnológicas existentes que permitissem o compartilhamento e preservação do dialeto indígena. $\mathrm{O}$ levantamento realizado identificou 2 soluções estrangeiras ("Idiomas em Risco" e "Aikuma") que atendiam o Brasil, mas que não abrangiam significativamente a demanda apresentada pelas aldeias brasileiras, registrar a forma escrita e a pronúncia de palavras indígenas. Os sistemas analisados garantem em parte a preservação oral sem, contudo fazer um relacionamento com a língua oficial do país ou permitir a separação de palavra por palavra juntamente com seu sinônimo em português. Era preciso garantir o armazenamento escrito da língua indígena de modo a caracterizar uma identidade gráfica para as línguas nativas existentes no Brasil.

Se além de falar o índio conseguir escrever sua língua isso representará um ganho tanto para o povo indígena quanto para a cultura linguística brasileira, na medida em que aquele registro não se perderá com o tempo, mesmo que aquela língua deixe de ser falada e desapareça do ponto de vista oral.

A grande distância entre as aldeias existentes serviu para perceber que uma ferramenta tecnológica e on-line pode ser uma alternativa para permitir a colaboração síncrona entre tribos/comunidades em áreas geograficamente distantes, a integração deve acontecer em uma rede de informações onde os dados coletados e suas análises são armazenados na base de dados, possibilitando aos usuários sua reutilização e construção de novos aprendizados. O uso de sistemas para o armazenamento da cultura indígena possibilita a troca de informações entre as comunidades.

A existência de um sistema para catalogar as palavras indígenas além de apresentar a imagem e a pronúncia (som) funcionaria como um local de consulta e estudo por parte dos índios interessados, além de representar um material audiovisual sempre à disposição para aprendizado e disseminação da língua indígena.

Diante de todas essas análises e observações foi desenvolvido o Sistema para Catalogar Palavras Indígenas (SISCAPI), a fim de solucionar ou amenizar os problemas identificados na pesquisa, o sistema é discutido e mostrado no próximo tópico.

\section{O SISCAPI como meio de preservação das palavras indígenas}

O armazenamento de dados é empregado no SISCAPI, visto que busca promover a integração do vocabulário indígena através do cadastro e armazenamento das palavras indígenas (texto, som e imagem). No sistema o usuário acessa a página para solicitar participação e assim contribuir no cadastramento de novas palavras ou ainda recuperar/pesquisar as já cadastradas. O acesso às informações detalhadas referente aos usuários, línguas e povos acontece através de autenticação, enquanto que as palavras cadastradas estão disponiveis aos visitantes pois integram um acervo global de línguas indígenas de modo a tornar-se um patrimonio cultural e serem mais facilmente preservadas. A Figura 1 exemplifica a disponibilidade e apresentação das informações cadastradas no sistema. 
CBIE-LACLO 2015

Anais dos Workshops do IV Congresso Brasileiro de Informática na Educação (CBIE 2015)

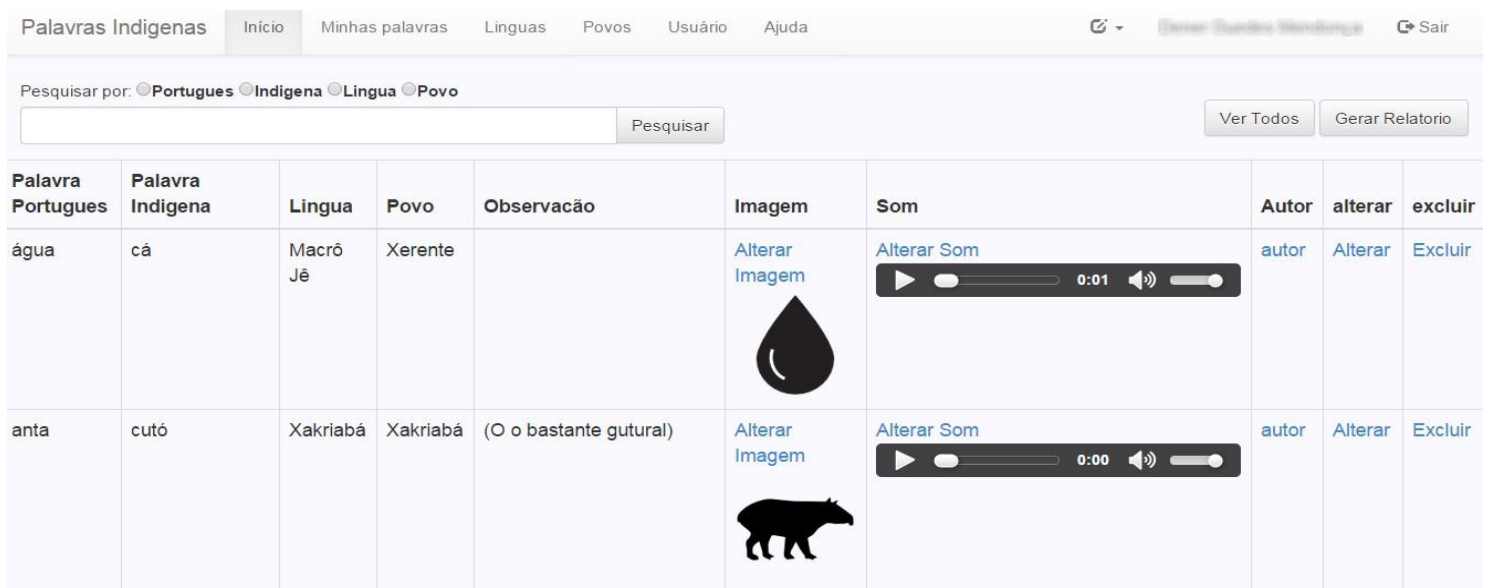

Figura 3. Palavras indígenas armazenadas; Fonte: SISCAPI (2015).

O SISCAPI busca integrar os povos indígenas através de seus dialetos, utilizando-se deste sistema que será de domínio público. Certa padronização de termos se fez necessário para facilitar o intercâmbio linguístico. Manter esses princípios é de fundamental importância para que o sistema funcione com segurança e de forma confiável, assim ele será possivel auxiliar e garantir a sua propria sustentabilidade.

No sistema é possível gerar um documento PDF (Figura 2) com as palavras já cadastradas, isto facilita estudos posteriores, análise e comparação das informações, funciona como um minidicionário sempre a disposição, além de ser um registro documental daquela determinada língua.

\section{Palavras Indígenas}

Relatório com todas as palavras indígenas cadastradas no sistema

Para saber mais acesse: www.palavrasindigenas.com.br

\begin{tabular}{|c|c|c|c|c|}
\hline $\begin{array}{c}\text { Palavra } \\
\text { Portugues }\end{array}$ & Palavra Indígena & Lingua & Povo & Observação \\
\hline água & cá & Macrô Jê & Xerente & \\
\hline anta & cutó & Xakriabá & Xakriabá & (O o bastante gutural) \\
\hline árvore & odé & Xakriabá & Xakriabá & \\
\hline boca & daidaua & Xakriabá & Xakriabá & \\
\hline boca & dácedaná & Macrô Jê & Xerente & $1 \Gamma$ \\
\hline
\end{tabular}

Figura 2. PDF das palavras indígenas cadastradas no sistema; Fonte: SISCAPI (2015).

O sistema foi construido baseado na experiência línguistica indígena tendo como base a comunidade Xakriabá. A uso via web atende a demanda apresentada nesta aldeia. Toda a comunicação e interação com o usuário acontece através do navegador web onde são oferecidas as interfaces, fornecidadas e requisitadas as informações de povoamento do sistema.

\section{Considerações Finais}

O aprendizado indígena esta cada vez mais ligado a seu cotidiano e as necessidades do mundo contemporâneo, não apenas o conhecimento teórico é almejado por esses povos, mas a busca do saber como um projeto societário para se alcançar outros, sempre na direção da autonomia indígena. Se existe uma demanda indígena voltada para a 


\section{CBIE-LACLO 2015}

Anais dos Workshops do IV Congresso Brasileiro de Informática na Educação (CBIE 2015)

preservação de seus costumes, línguas e características, é porque a existência dessas informações é almejada. Neste contexto o uso da tecnologia torna-se necessário para proporcionar condições de aprendizado dos vocabulários indígenas através dos suportes técnicos digitais para que o conhecimento seja então efetivamente assimilado pelos índios.

Na comunidade dos Xacriabás já existem escolas, professores indígenas que utilizam a tecnologia e também a internet para pesquisa e comunicação, recursos pedagógicos de audiovisual, redes sociais, e-mails, etc. A disponibilização do vocabulário indígena próprio on-line pode ser uma alternativa para tornar o aprendizado agradável, fazer com que o índio se sinta inserido na construção do conhecimento e capaz de lidar com os diversos recursos tecnológicos. Compreende-se que o processo da cosntruação e transferência do conhecimento perpassa pela importância da informação. O valor da informação, muitas vezes não é facilmente mensurável, pois depende de seus usuários. Atualmente a transferência desses costumes e conhecimentos são realizados oralmente. Entretanto, observa-se uma tendência das comunidades indígenas de se comunicarem através de redes sociais, e isso pode vir a ser considerado como uma alternativa viável para a sua interação e desenvolvimento. $\mathrm{Na}$ medida em que as comunidades se aderem aos recursos tecnológicos, nota-se a tendência a alterar as suas estruturas e costumes. Porém, as transformações requerem novas tecnologias e maneiras de se organizar, capazes de dar suporte à transferência de conhecimentos e informações. Com vistas a tentar amenizar a carência e preencher esta lacuna é que o SISCAPI se propõe a servir de meio no processo de armazenar e preservar a cultura linguística indígena (escrita e falada).

A adoção de sistemas se traduz em alternativas viáveis e muitas vezes necessárias para a sobrevivência de uma cultura (em especial as das pequenas comunidades), visto que o isolamento as torna incapazes de acompanhar o ritmo de mudanças e as exigências de atualização tecnológica. O Sistema tem por objetivo prover uma forma de se organizar e disponibilizar o acesso a um maior número de pessoas sem perder as suas raízes. Compreende-se que sem a garantia do acesso, o seu uso não é efetivo, e, portanto deixando de cumprir com sua função enquanto recurso on-line, cujo benefício é a maior disponibilidade de um vocabulário on-line. Desse modo, observa-se que o SISCAPI pode ser uma ferramenta a ser utilizada por diversas tribos, associandoas a cada língua indígena existente e construindo uma base de dados culturalmente importante.

A formação de uma base de dados é uma forma de se armazenar a evolução de um estudo. Dados coletados (palavras) pelos usuários de uma comunidade e armazenados podem ser consultados por outros usuários que podem fazer novas coletas, agregando novos significados. Com uma base de dados com referência para comparar, realizar análise ou mesmo reutilização em uma estrutura on-line as possibilidades são ilimitadas. A utilização de sistemas para preservação e compartilhamento do vocabulário indígena não faz com que a aldeia perca sua cultura ou língua para o ambiente digital, pelo contrário ajuda a preserva-la, pois como acontece com os sistemas de armazenamento de informação globais o conhecimento se tornará mais amplo, permitindo que a comunicação melhore e que o projeto de preservação linguística ganhe a adesão de todos. 


\section{CBIE-LACLO 2015}

Anais dos Workshops do IV Congresso Brasileiro de Informática na Educação (CBIE 2015)

Assim, averiguou-se que os principais problemas apontados em relação aos trabalhos relacionados foram solucionados ou amenizados. O SISCAPI já está disponível na web no endereço eletrônico www.palavrasindigenas.com.br onde é possível conhecer um pouco mais sobre suas funções e solicitar a participação. $\mathrm{Na}$ análise geral conclui-se que mesmo existindo outros sistemas voltados ao resgate línguistico indígena, o SISCAPI se apresenta como uma opção adequada a realidade das tribos brasileiras.

\section{Referências Bibliográficas}

Albano, Cláudio Sonáglio. (2012). "A Percepção da Gestão do Conhecimento: Estudo de Caso na Área de Tecnologia da Informação em uma Universidade Federal." In Anais do VIII Simpósio Brasileiro de Sistemas de Informação (SBSI).

Beal, Adriana. (2007). "Introdução a Gestão da Tecnologia da Informação." BrasíliaDF. Disponível em http://migre.me/qkqvR. Acesso em nov/14.

Brito, Lydia Maria Pinto. (2008). "Gestão do conhecimento - instrumento de apropriação pelo capital do saber do trabalhador." Pelotas-RS. Disponível em http://migre.me/qkpF5. Acesso em dez/14.

Escobar, Suzana Alves. (2012). "Os projetos sociais do povo indígena xakriabá e a participação dos sujeitos: entre o "desenho da mente", a "tinta no papel" e a "mão na massa" ". Pós-Graduação em Educação: Conhecimento e Inclusão social. UFMG Faculdade de Educação. Belo Horizonte-MG.

. (2011). "Letramento Xakriabá - As Vozes, a Escrita e o

Poder”. Ondina-BA. Disponível em http://migre.me/qkpjI. Acesso em dez/14.

Gallois, Dominique T,; Carelli, Vicent. (1998). "Índios eletrônicos: uma rede indígena de comunicação". São Paulo. Disponível em http://migre.me/mNI6F. Acesso em $\mathrm{jan} / 15$.

Kleina, Nilton. (2012). "Google lança projeto para preservar idiomas em extinção". Disponível em http://migre.me/qkpRw. Acesso em fev/15.

Lima, J. F.. (2013). “Arquitetura em Rede de Compartilhamento de Laboratórios Online". Tese de Doutorado. Programa de Pós-Graduação em Engenharia Elétrica. Universidade de Brasília-DF.

Neher, Clarissa. (2013). "Projeto usa smartphone para preservar línguas indígenas". Disponível em http://dw.de/p/18F8h. Acesso em fev/15.

Oliveira, Djalma de Pinho Rebouças de. (2002). "Sistemas, organizações e métodos: uma abordagem gerencial”. 13. ed.; Ed. Atlas. São Paulo-SP.

Padoveze, Clóvis Luís. (2000). "Sistemas de Informações Contábeis: fundamentos e análise”. 2. ed., Atlas. São Paulo-SP.

Renesse, Nicodème. (2010). "O que pensam os índios sobre a presença da internet em suas comunidades?”. São Paulo-SP. Disponível em http://migre.me/mNHsU. Acesso em fev/15.

Zednik, Herik. (2014). "Tecnologias Digitais na Educação: proposta taxonômica para apoio à integração da Tecnologia em sala de aula". In Anais do $3^{\circ}$ Congresso Brasileiro de Informática na Educação (CBIE). 